\title{
Uma modelagem conceitual para apoiar a identificação das causas da evasão escolar em EAD
}

\author{
Vanessa da Silva Ferreira ${ }^{1}$, Marcos da Fonseca Elia ${ }^{2}$ \\ 1,2 Programa de Pós Graduação em Informática (PPGI) - Universidade Federal do Rio \\ de Janeiro (UFRJ) \\ infovanessa@gmail.com,melia@nce.ufrj.br
}

\begin{abstract}
In this article we present a systemic view of the scene of Brazilian Distance Education through the use of modeling, represented in the form of Systemic Networks. This vision will enable the registration of paradigms, especially those that depict the causes of School this teaching modality. Our focus is to share a Network Systemic initial structured from the analysis of metadata to record the collaborative paradigms that possibly lead to avoidance of such courses, coordinators designated by Higher Education Institutions.
\end{abstract}

Resumo. Neste artigo, apresentamos uma visão sistêmica do cenário da Educação à Distância Brasileira através do uso de modelagem conceitual, representada na forma de Redes Sistêmicas. Esta visão possibilitará o registro de paradigmas, especialmente os que retratam as causas da Evasão Escolar desta modalidade de ensino. Nosso foco é compartilhar uma Rede Sistêmica inicial estruturada a partir da análise de metadados para registro colaborativo dos paradigmas que possivelmente levam a evasão de tais cursos, indicados por coordenadores de Instituições de Ensino Superior.

\section{Introdução}

A educação a distância atrelada às tecnologias de informação e comunicação (EAD/TIC ou doravante EAD) surge como uma estratégia das políticas públicas brasileiras dos últimos 15 anos para a democratização e propagação do ensino, especialmente na formação superior, continuada e no aperfeiçoamento profissional. Neste período, surgem Decretos de Lei, Resoluções e Portarias Normativas implementadas pelos governos na busca da inserção da população no ensino. Essas estratégias surgem também em parte para atender uma demanda da sociedade baseada no conhecimento em acompanhar a revolução tecnológica dos últimos tempos, que atua em todos os setores desta sociedade, especialmente na educação. A EAD como modalidade de ensino encurta distâncias, promove a autonomia, a coletividade e realiza o processo de ensino e aprendizagem em locais onde o ensino presencial não pode atuar por diversos motivos.

Apesar de todas as estratégias e atos governamentais e de tantos atrativos, a EAD tem índices consideráveis de evasão, especialmente nas instituições de ensino superior (IES). Sabe-se que a evasão pode acontecer por diversos motivos, desde o desinteresse do aluno ou necessidade de trabalhar, até o mau planejamento do curso oferecido. 
A motivação deste estudo é justamente compreender por que uma forma de ensino tão inovadora e atual tem dados que, por um lado, expressam de forma bem significativa o interesse da população na busca por tais cursos oferecidos em EAD e, por outro lado, contrasta com a alta desmotivação e o baixo índice de concluintes destes cursos.

Para tal, acredita-se, como premissa deste estudo, que seria necessário compreender toda a estrutura montada e percorrida pela EAD em sua fundamentação para o oferecimento destes cursos. Entende-se que uma modelagem conceitual pode auxiliar esta compreensão, permitindo uma análise qualitativa e quantitativa, de caráter sistêmico.

A partir desta ideia, buscou-se identificar se existiria na literatura alguma modelagem conceitual que permitisse analisar de forma mais abrangente a situação da EAD no Brasil, especialmente a evasão percebida nesta modalidade, mas as pesquisas feitas até o presente momento revelam uma visão apenas fragmentada destes conceitos.

Decidiu-se então, primeiramente, construir uma visão sistêmica da EAD a partir de uma base de metadados formada por uma amostra de artigos selecionados, ficando a evasão a ser tratada como parte deste todo. E como estratégia para sua construção adotou-se a forma de representação denominada redes sistêmicas (RS) [Bliss, Monk \& Ogborn 1983]. Para análise e compreensão dessas informações, utilizou-se o método de análise de conteúdo [Bardin 1977].

Como os artigos utilizados na construção dos metadados vieram de diversas regiões do país, decidiu-se também desenvolver uma metodologia de entrevistas a distância (online) com fins de validação do trabalho realizado.

Este artigo é composto por seis seções incluindo esta primeira de caráter introdutório, a segunda com uma revisão da literatura sobre os temas envolvidos, a terceira com a solução proposta desta pesquisa, a quarta com a metodologia da pesquisa e os instrumentos utilizados, a quinta com os resultados e a sexta, por fim, com as considerações finais.

\section{Revisão da Literatura}

A educação a distância no Brasil tem sido tratada pelo governo através de Leis, Diretrizes e Normas regulamentares ao longo da última década e tem sido tema frequente em pesquisas e trabalhos realizados nestes últimos anos. Pesquisadores, como [Moore e Kearsley 2007], [Maia e Mattar 2007], [Martins 2005], [Belloni 2002], [Niskier 2000], refletem sobre a EAD, a forma como ela disponibiliza em grande escala acesso à educação de quem não tem condições de frequentar a escola presencial e se utiliza de recursos computacionais para acesso ao ensino, em seu tempo e espaço e expressam a carência de maior aprofundamento do tema, pois estes têm diferentes conceitos para as definições de temas pertinentes a área, como tempo, distância, educação e ensino.

Para Niskier (2000), "Parte-se de um conceito extremamente simples: alunos e professores separados por certa distância e, às vezes pelo tempo. A modalidade modifica aquela velha ideia de que, para existir ensino, seria sempre necessário contar com a figura do professor em sala e de um grupo de estudantes".

Uma visão mais crítica sobre o uso em grande escala da EAD como políticas públicas é apresentada. Para Elia (2005), "no meio de condições acadêmicas e políticas 
tão favoráveis surge novamente, de fora e de dentro do país, o risco de soluções milagrosas para uma inclusão rápida dessa maioria de excluídos, particularmente, no ensino superior".

A EAD, assim como a educação presencial, sofre com os índices de evasão. A percepção de suas causas é importante num país que precisa cuidar da educação ao máximo, em todos os níveis de ensino, especialmente, no Ensino Superior. As supostas causas quanto à evasão em cursos à distância surgem por falta de domínio técnico do computador e da internet, na falta da relação presencial entre professores e alunos e na dificuldade de expor ideia numa comunicação escrita à distância [Silveira 2012].

A evasão refere-se à desistência definitiva do estudante em qualquer etapa do curso, e a mesma pode ser considerada como um fator frequente em cursos à distância [Santos et. al. 2008].

Com isso, ratifica-se a necessidade de identificação das causas da evasão em EAD dentro de instituições de ensino superior, para que seja viável traçar medidas eficazes para que tais índices sejam reduzidos.

Para apoio ao estudo desta pesquisa, em sua primeira fase foram escolhidos alguns artigos que tratam estudos de casos em instituições de ensino superior que ofereciam cursos em EAD e as possíveis causas de evasão destes cursos. Estes artigos também foram publicados por [Santos et. all. 2008], [Silveira 2012], [Souza 2008], [Jorge et. all. 2010].

As RS utilizadas para representar as informações descrevem qualitativamente as relações existentes entre variáveis, melhorando consideravelmente o nível de informação, sendo efetivamente aplicadas em trabalhos na área educacional [Bliss, Monk \& Ogborn 1983],[Chamovitz 2004].

As ferramentas computacionais encontradas na literatura que foram utilizadas para construir as RS e para fazer as entrevistas online serão referenciadas neste artigo como [Ferramentas, 2013] e foram descritas dentro do contexto da presente pesquisa (Seções 4.1 e 4.2).

Para fazer a análise dos dados obtidos através dos metadados e das entrevistas com coordenadores das IES, foi utilizada uma abordagem qualitativa denominada técnica de análise de conteúdo, desenvolvida por Bardin (1977), o qual define "que esta análise, enquanto método se torna um conjunto de técnicas de análise das comunicações utilizando procedimentos sistemáticos e objetivos de descrição do conteúdo das mensagens".

\section{Solução proposta}

A proposta deste trabalho tem como objetivo maior identificar as causas da evasão em cursos de graduação oferecidos na modalidade de Educação à Distância, através da construção de um modelo conceitual sistêmico. Assim, relacionados a este objetivo geral estão associados os seguintes objetivos mais específicos:

1. Modelo conceitual sistêmico, identificar uma forma de representação e organização da informação de um modelo conceitual sobre a EAD que permita percorrer e visualizar sistemicamente toda estrutura da EAD para a análise de evasão escolar desta modalidade;

2. Evasão escolar, fazer um levantamento dos indicadores de evasão escolar e propor um indicador padronizado e identificar as principais causas geradoras da evasão em EAD, para diferentes cenários, propondo soluções; 
3. Metodologia para entrevistas online, criar uma estratégia que permita o debate entre pesquisadora e entrevistado, utilizando ferramentas disponíveis no mercado para a construção de RS colaborativas.

\section{Metodologia}

As pesquisas referentes à construção do modelo conceitual e à evasão escolar seguem o estilo conhecido na literatura como "Levantamento de dados", em parte, de natureza documental, pois está baseada em análises quantitativas e qualitativas de conteúdos legislativos (Leis, Decretos, Portarias Normativas), em parte de natureza acadêmica, tais como um estudo índices de evasão em EAD e seleção de trabalhos relacionados à área, e, em parte também, através da experiência pessoal da autora. Além disso, utilizou-se um procedimento recursivo, descrito na seção 4.2, para construção do modelo conceitual através do uso de RS.

Para validação dos resultados, estão sendo consideradas duas metodologias complementares, ambas utilizando entrevistas online com os responsáveis por cursos de EAD pertencentes a uma amostra: (i) equivalente àquela que foi utilizada na fase dos metadados; e (ii) formada por cursos da cidade onde se realiza a pesquisa.

\subsection{Instrumentos}

\subsubsection{Redes Sistêmicas (RS)}

Redes sistêmicas demonstram, de certo modo, um estudo global de um determinado assunto, expressando uma visão sistêmica, ou seja, estudar as partes levando em consideração o seu papel no funcionamento do todo, buscando uma representação da informação e análise qualitativa de dados que podem ser implementadas cooperativamente [Bliss, Monk \& Ogborn 1983]. Estas redes são utilizadas para avaliar dados qualitativos através da categorização de seus principais aspectos buscando atingir tal estrutura e facilitar a análise e a interpretação dos dados obtidos na pesquisa, permitindo que os metadados (artigos) e entrevistados possam observar uma rede sistêmica inicial gerada, moldando-a a sua realidade, colaborativamente.

Uma RS tem uma sintaxe básica formada respectivamente por chaves " $\{$ " e colchetes "[" que representam uma conjunção de conceitos na forma aditiva ("e") e alternativa ("ou"). O uso combinado destes e outros recursos sintáticos disponíveis permitem expressar de forma sucinta uma visão sistêmica de um determinado assunto através de paradigmas que são considerados um entre vários padrões ou caminhos específicos na rede, composto por termos integrantes deste caminho, permitindo sua instanciação [Bliss, Monk \& Ogborn 1983].

\subsubsection{Ferramentas web}

Para obter dados e permitir a colaboração, foi realizada uma pesquisa sobre tecnologias TI para viabilizar todo processo. Primeiramente optou-se em utilizar ferramentas web priorizando o fácil acesso e disponibilidade. Para tal, dentre as ferramentas existentes, optamos pelo uso do Skype [Ferramentas, 2013], que permite a conversação online com vídeo e compartilhamento de tela, do VodBurner [Ferramentas, 2013], que permite a gravação das entrevistas realizadas pelo Skype, e do MindMeister [Ferramentas, 2013], 
que permite a construção de modelagem conceitual e registro de paradigmas de forma intuitiva e colaborativa.

Destacamos a adaptação do MindMeister com a simbologia própria para registro das redes sistêmicas, conforme descrito na seção 4.1, visto que originalmente esta ferramenta foi idealizada para registro de mapas mentais, mas esta permite a adaptação através de imagens, conforme ilustrado na figura 1.

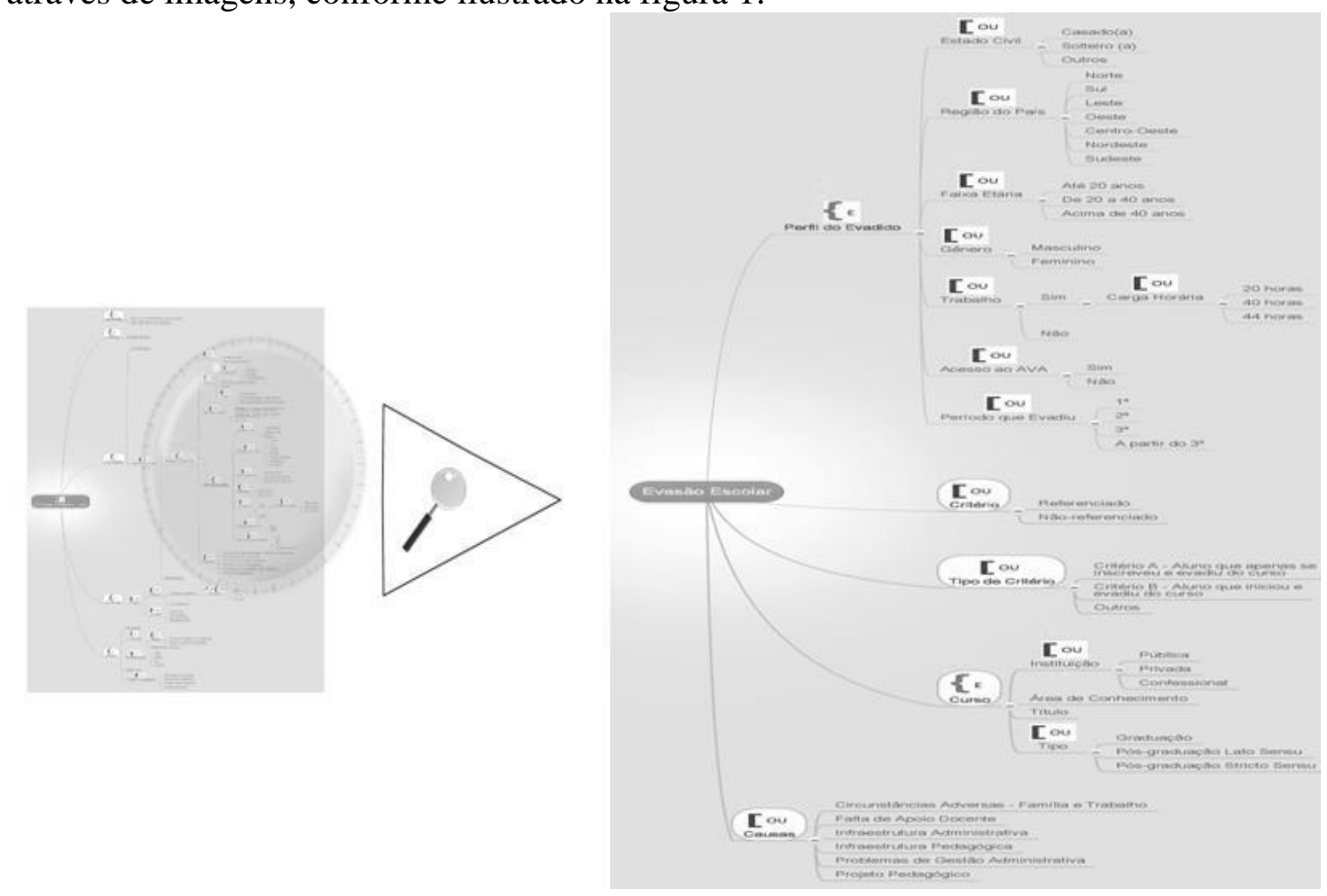

Figura 1: RS da EAD no Brasil gerada a partir dos metadados, com adaptação do MindMeister, com destaque para os paradigmas da Evasão Escolar.

\subsection{Procedimentos}

\subsubsection{Construção da RS}

Para a construção da RS que represente a evasão escolar em EAD, foi utilizada inicialmente uma RS baseada na pesquisa documental e na experiência da autora, seguindo a seguinte dinâmica:

a. Selecionam-se artigos na literatura que tratam da evasão escolar em EAD para constituir uma base de metadados;

b. Analisam-se os artigos utilizando técnicas de análise de conteúdo;

c. Confronta-se a RS inicial com o resultado da análise do item b, fazendo-se os ajustes necessários para que a RS modificada instancie satisfatoriamente as categorias e relações observadas nos artigos em tela;

d. A nova RS é então confrontada da mesma maneira com um segundo artigo e fazem-se os mesmos procedimentos de ajustes gerando outra RS;

e. Os procedimentos acima são então repetidos respectivamente com todos os demais artigos até que se alcance uma autoconsistência satisfatória. 
A figura 2 ilustra as fases b, c e d da seção 4.2.1. Neste exemplo registram-se as categorias e relações observadas no artigo pela análise de conteúdo para fins de validação interna da RS. No termo "perfil do evadido", o subtermo "faixa etária" sofreu alterações para adaptação da RS nos seus valores de abrangência que anteriormente tinham as faixas "até 35 anos", de "36 a 45 anos", "acima de 45 anos". Os novos valores para atender este e outros metadados foram atribuídos para "até 20 anos", "de 21 a 40 anos" e "acima de 40 anos".

O termo "trabalha" sofreu alterações. O subtermo "tempo de trabalho" foi substituído por "carga horária semanal", com faixas de valores de "20 horas", "40 horas" e "44 horas".

A nova RS recebeu mais um termo em seus paradigmas, atribuído para "período que evadiu", com subtermos com faixas de valores de " $1^{\circ}$ período", " $2^{\circ}$ período", " 3 ” período" e "a partir do $3^{\circ}$ período".

Estas mudanças com a aplicação dos itens $b, c$ e $d$ da dinâmica da construção da RS permitem a instanciação das IES analisadas, registrando-as na RS, descrevendo o caminho percorrido pelos dados, permitido a visualização de paradigmas que identifiquem as possíveis causas de evasão escolar.

Em uma rede sistêmica, um paradigma é observado percorrendo o caminho compreendido entre o termo inicial e outro mais afastado, seguindo-se o "galho" da rede apresentada. Como a RS proposta reflete uma visão sistêmica da EAD, pode-se percorrer por outros paradigmas, a fim de se tomar estratégias preventivas a estas causas. A comparação de paradigmas facilita a análise dos dados [Chamovitz 2004]. Por exemplo, a RS da figura 1 representa a visão final obtida a partir da análise descrita na seção 5 sobre a EAD no Brasil.

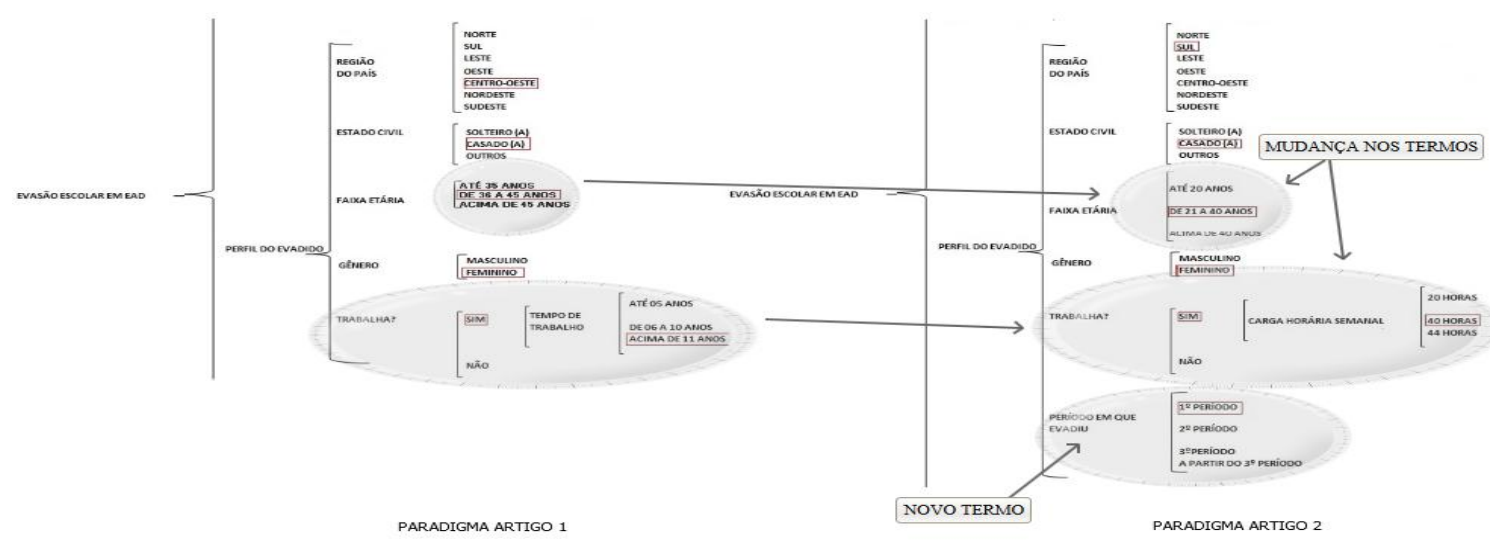

Figura 2. Exemplo da dinâmica da construção da Rede sistêmica no paradigma da Evasão Escolar.

\subsubsection{Entrevistas online}

As entrevistas para coleta de dados ocorrem de forma online, utilizando as ferramentas web descritas na seção 4.1 para que possam atender as IES da amostra selecionada.

Para as entrevistas online, foi criada uma estrutura que contempla os procedimentos a serem seguidos, recortando a coleta de dados em três fases: antes, durante e depois da entrevista, descritos a seguir. A figura 3 ilustra esquematicamente o planejamento para a entrevista, enquanto que os quadros 1-3 detalham os procedimentos para cada etapa: 


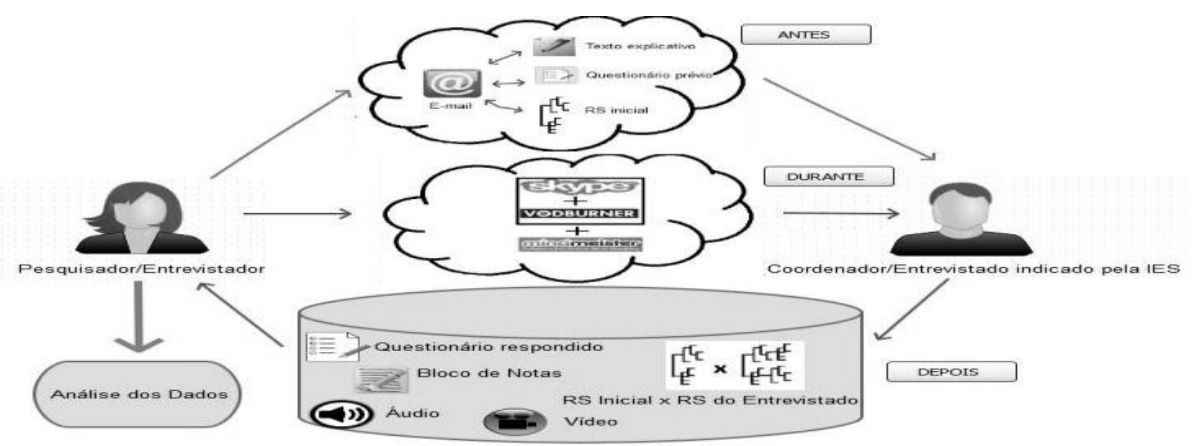

Figura 3: Planejamento para obtenção da Rede sistêmica da EAD no Brasil gerada a partir dos metadados, com adaptação do MindMeister.

\title{
Quadro 1- Fase antes da entrevista
}

\author{
Antes da entrevista \\ Para o bom andamento da entrevista, tivemos a preocupação com algumas atividades:
}

Preparo da carta convite: encaminhada via e-mail às IES que foram contempladas na escolha por amostra probabilística, a qual apresenta a proposta da pesquisa de dissertação e solicita a indicação do coordenador dos cursos em EAD para entrevista. Para retorno deste convite, podem ocorrer as seguintes situações: a) a IES aceitar o convite indicando que deseja participar da pesquisa e o contato do coordenador dos cursos; b) a IES indicar que não deseja participar da pesquisa e c) a IES não responder o e-mail.

Preparo do texto explicativo: encaminhado via e-mail ao entrevistado, mediante confirmação do item (a) indicado acima, informando-o sobre a realização da entrevista, agendamento, procedimentos e questionamento geral da pesquisa, com três possibilidades de enquadramento da resposta. Para tal, lança-se a questão ao entrevistado, solicitando a ele que retorne sua opção de resposta por e-mail, antes da entrevista online, acompanhada de uma justificativa: em que medida a Rede Sistêmica em tela representa a situação do(s) curso(s) coordenado(s) pelo colega? Para as possíveis respostas temos as opções abaixo, as quais vão compor a estratégia da entrevista e adequação da Rede sistêmica inicial a realidade da IES do entrevistado:

SIM - a RS proposta atende de forma geral (representa a realidade da IES que atuo);

SIM MAS - a RS atende em alguns pontos, mas entendo que necessita de alteração;

NÃO - a RS não atende, precisa ser refeita (não representa a realidade da IES que atuo);

Seguirá também em anexo no e-mail os seguintes documentos: Rede Sistêmica inicial criada a partir dos metadados, para que o entrevistado a analise, confrontando com a situação de sua IES; Breve explicação sobre o conceito de Redes Sistêmicas, a fim de ambientá-lo sobre esta forma de modelagem conceitual; Questionário prévio com questões que abordam cinco categorias (EAD, Evasão escolar em EAD, IES, Corpo Discente e Corpo docente) importantes para o registro do perfil do curso coordenado pelo entrevistado.

\section{Durante a entrevista}

\section{Quadro 2 -Fase durante a entrevista}

Instrumentos utilizados: teremos as ferramentas anteriormente citadas que permitirão, no seu uso em conjunto, a visão sistêmica de toda estrutura de EAD elaborada previamente, de forma que o respondente, durante a entrevista, se sinta envolvido no processo e motivado para responder as perguntas da maneira mais sincera possível. Além disso, o fato de estar imerso na rede sistêmica, fará com que ele se localize dentro dela e responda a questão solicitada levando em consideração o contexto desta questão dentro da rede. Ao final, espera-se registrar na rede sistêmica a instanciação de paradigmas que retratará as possíveis causas de Evasão.

Procedimentos durante a entrevista: teremos a utilização das ferramentas web Skype, VodBurner e MindMeister, do Bloco de notas, que constará de anotações feitas durante a entrevista de falas importantes do entrevistado, de um questionário prévio com questões para formar o perfil do curso e base para aplicação do protocolo customizado mediante resposta a questão de pesquisa previamente enviada pelo entrevistado.

\section{Depois da entrevista}

Dados disponíveis para análise:

Respostas obtidas do questionário prévio para o perfil do curso;

Rede sistêmica inicial dos metadados;

Rede sistêmica gerada pelo entrevistado;

Áudio e vídeo da entrevista;

Anotações do bloco de notas.

Análise utilizando técnicas de Bardin (1977) permitirá a visão dos seguintes parâmetros para validação da 
Rede Sistêmica representativa da EAD no Brasil, com ênfase na Evasão Escolar:

Confiabilidade: analisar a constância dos dados obtidos quando as IES forem avaliadas mais de uma vez, em diferentes métodos de avaliação;

Consistência: analisar se a Rede gerada é consistente, tanto a gerada na fase dos metadados quanto na análise dos dados obtidos junto as IES entrevistadas;

Veracidade: analisar a significância dos dados coletados, comprovando a verdade dos mesmos dados a necessidade de avaliação do grau de verdade do que foi registrado verificando se não há contradições ou dúvidas sobre os dados;

Validação: analisar se a Rede Sistêmica é capaz de medir o fato que se propõe a medir, ou seja, validar se de fato a Rede representa numa visão sistêmica a situação atual da Educação à Distância no Brasil, especialmente se registra as causas da Evasão Escolar nesta modalidade.

\section{Resultados}

Os resultados obtidos nesta pesquisa refletem a consecução de suas metas inicialmente propostas: construção de um modelo conceitual sistêmico, identificação das causas de evasão em EAD e uma contribuição de natureza procedural: a metodologia utilizada na fase dos metadados e das entrevistas online.

Para o modelo conceitual tomamos como fonte os dados apresentados por artigos publicados que tratavam de estudos de caso de IES distintas, indicando alguns fatores que possivelmente levaram a evasão em cursos oferecidos as IES analisadas, servindo para esta pesquisa como metadados.

Inicialmente foi feita uma leitura dos artigos [Souza 2008], [Santos et al 2008], [Jorge et al 2010], [Silveira 2012] e um levantamento das causas de evasão indicada por estes, surgindo, ao final, 15 possíveis causas, sendo estas: fatores situacionais; falta de apoio acadêmico; problemas com a tecnologia; falta de apoio administrativo; sobrecarga de trabalho; organização do curso; problemas pessoais; relação com o professor-tutor; aprendizagem; tecnologia; relação interpessoal; limite pessoal; limite profissional; condições do polo e aspectos referentes ao curso e tutoria.

A análise de conteúdo atua com referenciação de índices e a elaboração de indicadores [Bardin 1977]. Permite a possibilidade de enquadrar falas distintas, especialmente em relação às causas de evasão. Nesta pesquisa, para categorização dos índices indicadores de evasão escolar a análise de conteúdo foi feita com base nos artigos dos metadados, com base nas causas identificadas e indicadas no quadro 4 .

Com a análise, é possível perceber que algumas causas identificadas podem ser agrupadas, formando uma categorização. Esta categorização foi realizada da seguinte forma:

1. Na exploração dos artigos, faz-se uma codificação permitindo uma identificação do conteúdo;

2. Esta identificação revela duas unidades: unidades de registro e unidades de contexto:

a. As unidades de registro vão fornecer os termos agregadores, aqueles aos quais as causas obtidas na análise dos metadados serão agrupadas;

b. As causas agrupadas serão as unidades de contexto, que vão permitir a compreensão dos termos agregadores.

Após estes procedimentos, temos o seguinte resultado que apontam, ao invés de 15, para 06 causas sistêmicas. 
Quadro 4. Análise de Conteúdo dos metadados.

\begin{tabular}{|c|c|c|c|}
\hline Categoria & Subcategoria & Unidades de registro & Unidades de controle \\
\hline \multirow[t]{6}{*}{ Evasão escolar } & \multirow[t]{6}{*}{ Causas } & Circunstâncias adversas: pessoal, família e trabalho. & $\begin{array}{l}\text { Fatores situacionais; } \\
\text { Sobrecarga de trabalho; } \\
\text { Problemas pessoais; } \\
\text { Aprendizagem; } \\
\text { Tecnologia; } \\
\text { Relação interpessoal; } \\
\text { Limite pessoal; } \\
\text { Limite profissional; }\end{array}$ \\
\hline & & Falta de apoio docente. & $\begin{array}{l}\text { Falta de apoio academic; } \\
\text { Relação com o professor-tutor; } \\
\text { Aprendizagem. }\end{array}$ \\
\hline & & Infraestrutura Administrativa. & $\begin{array}{l}\text { Problemas com a tecnologia; } \\
\text { Organização do curso; } \\
\text { Condições do polo; } \\
\text { Aspectos referentes ao curso e tutoria. }\end{array}$ \\
\hline & & Problemas de gestão administrativa. & $\begin{array}{l}\text { Problemas com a tecnologia; } \\
\text { Falta de apoio administrativo. }\end{array}$ \\
\hline & & Infraestrutura Pedagógica. & $\begin{array}{l}\text { Sobrecarga de trabalho; } \\
\text { Relação com o professor-tutor. }\end{array}$ \\
\hline & & Projeto pedagógico. & $\begin{array}{l}\text { Organização do curso; } \\
\text { Tecnologia; } \\
\text { Condições do polo; } \\
\text { Aspectos referentes ao curso e tutoria. }\end{array}$ \\
\hline
\end{tabular}

A contribuição metodológica procedural é dada pelo seguinte esquema: a utilização da dinâmica na construção da $\mathrm{RS}$, detalhadas na seção 4.2.1 somada às técnicas de análise de conteúdo de Bardin.

Pode-se assim inferir que foi obtida até este momento uma rede internamente consistente, especialmente no paradigma que evidencia as possíveis causas da evasão escolar que produz realmente uma visão sistêmica junto a RS final e que permite olhar a evasão como um todo, registrando sua ramificação na RS.

Para a metodologia da entrevista online, na coleta de dados, todo procedimento descrito na seção 4.2.2 no quadro 1 (antes da entrevista) foi realizada. Através de uma amostra probabilística por etapas, 14 IES espalhadas por todas as regiões brasileiras receberam nosso contato inicial. Destas IES, 05 retornaram demonstrando interesse em participar da pesquisa. E dentre as IES que demonstraram interesse, somente 01 teve a entrevista realizada. Para esta IES, os procedimentos descritos na seção 4.2.2 no quadro 2 (durante a entrevista) foram realizados e nos dados obtidos já foram realizados análise de conteúdo.

No momento, esta pesquisa retoma os procedimentos de uma nova amostra probabilística para continuidade da coleta de dados.

\section{Considerações finais}

Nossa proposta vem buscar, através de uma visão sistêmica, registrar as possíveis causas da Evasão Escolar em cursos em EAD oferecidos por Instituições de Ensino Superior, visto que até o momento só encontrou-se visões fragmentadas. Para tal, foi elaborada toda uma metodologia que possa proporcionar essa visão, através do uso de Redes Sistêmicas, para registro de paradigmas e instanciações e na coleta de dados de tais instituições espalhadas por todas as regiões brasileiras.

Espera-se, com o registro das causas de evasão, propor soluções para as Instituições de Ensino Superior atuarem preventivamente sobre tais causas, assim, também reduzindo os índices de evasão escolar que as afetam. 
Em relação a trabalhos e desdobramentos futuros, espera-se que "a RS final" (uma utopia) possa ser utilizada por outros pesquisadores para abordagens distintas, procurando respostas a outras questões específicas relacionadas à EAD.

\section{Referências}

BARDIN, L. Análise de conteúdo. Lisboa: Edições 70, 1977.

BELLONI, Maria Luiza. Ensaio sobre a educação a distância no Brasil. Revista Educação e Sociedade, Campinas, ano XXIII, n. 78, p. 117-142, abr. 2002.

BLISS, J., MONK, M., OGBORN, J. Qualitative Data Analysis for Educational Research: A guide of systemic networks. London: Croom Helm, 1983.

CENSO EAD.BR: relatório analítico da aprendizagem a distância no Brasil 2011. - São Paulo: Pearson Education do Brasil, 2012. ABED - Associação Brasileira de Educação a Distância.

CHAMOVITZ, Ilan. GRS: gerador de redes sistêmicas na web: um instrumento de apoio ao desenvolvimento cooperativo e a distância de atividades acadêmicas / Ilan Chamovitz. Rio de Janeiro: UFRJ/IM/NCE, 2004.

ELIA, Marcos da Fonseca. Uma nação em risco. In: SIMPÓSIO BRASILEIRO DE INFORMÁTICA NA EDUCAÇÃ̃O, 16, 2005, Juiz de Fora. Anais- Juiz de Fora: SBC, 2005. v. 1. p. 331-339.

Ferramentas (2013)

SKYPE: http://www.skype.com/pt-br/

VodBurner: http://www.vodburner.com/win

MindMeister: http://www.mindmeister.com/pt

JORGE, Bruno G, et al. Evasão na educação a distância: Um estudo sobre a evasão emuma instituição de Ensino Superior", 2010. Disponível em: http://www.abed.org.br/congresso2010/cd/252010220450.pdf Acesso em: 07/2012.

MAIA, C. MATTAR, João. ABC da EaD : a educação a distância hoje. São Paulo: Pearson Prentice Hall, 2007.

MARTINS, O. B. Fundamentos da educação a distância. Curitiba: IBPEX, 2005.

MOORE, M. e KEARSLEY, G. Educação a distância: uma visão integrada. São Paulo: Thomson Learning, 2007.

NISKIER, A. Educação a distância: a tecnologia da esperança. 2. ed. São Paulo: Loyola, 2000.

SANTOS, Elaine Maria dos, et al. "Evasão na Educação a Distância: identificando causas e propondo estratégias de prevenção", 2008. Disponível em: http://www.abed.org.br/congresso2008/tc/511200845607PM.pdf Acesso em: 07/2012.

SILVEIRA, Claudia Alexandra Bolela. Educação a distância e a evasão: Estudo de caso da realidade no polo UAB de Franca", 2012. Disponível em: http://sistemas3.sead.ufscar.br/ojs/index.php/sied/article/view/93. Acesso em: 07/2012

SOUZA, Onília Cristina de. Evasão em cursos a distância: análise dos motivos de desistência, 2008. Disponível em: http://www.abed.org.br/congresso2008/tc/552008112738PM.pdf. Acesso em: 07/2012.

STAKE,R.E. Case Studies, In: Denzin, N. K. e Lincoln, Y.S. Handbook of Qualitative Research. London: Sage Publications, 1994. 